Women \& Change in the Caribbean presents a number of challenges to scholars, and the contributors make a case for studying the experiences of Caribbean women that challenges Eurocentric and sexist perceptions and points the way forward. It also boldly presents a Black perspective in which the women need to be seen, studied and reflected upon with insight and understanding.

The incisive and stimulating studies revealed by the contributors showed women's capacity to construct, negotiate and develop their lives in creative, diverse and extraordinary ways.

I am pleased to say the author succeeded in presenting some very insightful, stimulating new material, strongly supported by active field research.

Claudette Williams

\title{
Compañeras: Voices from the Latin American Women's Movement
}

\section{Edited by Gaby Küppers}

Latin American Bureau: London, 1994

ISBN 090615686 6, f8.99/\$15.00 Pbk

Compañeras is the latest addition to the important new series of books on Latin America's women's movements from the Latin American Bureau. The series is especially welcome in Britain where the interest in Latin American politics and societies is growing. So, first let me record my thanks to the Latin American Bureau and encourage Feminist Review readers to make contact with and support the work of the Bureau. Raising the profile of Latin America is no easy task and overcoming the exoticization of the diverse cultures and peoples that are encompassed by this imaginary, 'Latin America', an even harder one. But, as the writings of Latin American intellectuals and activists do become available to English-speaking readers, they are offered a vision of the world far more optimistic than their own and one in which, despite the traumatic histories of Latin American states, the discourses within which politics is constructed are novel and affirmative. This is clearly evidenced in Compañeras.

The book, introduced by Gaby Küppers, is an inspiring set of interviews with women throughout Latin America, from the Andean cultures of Bolivia and Peru to the Caribbean of Haiti and the complexities of Brazil, Colombia and Cuba. The collection itself speaks for the diversity of the region and the growing sense of a Latin-Caribbean identity which is fuelled by shared politics and literature debated at the numerous women's 
events across the region. The interviews are organized around a series of themes that have resonances both globally and locally. The first of these is the question of autonomy for feminist and women's activism followed by the debate around the role of women in the social movements. The two come together in the third theme, 'Reclaiming Politics', the attempt to generate and support a feminist agenda within the political parties. Fourth is the vital articulation between human rights and women's rights. The final sections concern feminist publications and the future - 'Where Next?' The themes are intended as a starting point because, as the editor suggests, the collection is an open-ended one like the politics it seeks to convey.

Throughout the interviews there is no sense that women's movements in Latin America can speak with one voice or through a homogenized account of 'woman'. While some may be womanist the first recognition is the diversity of women and how this diversity is lived and theorized within the articulations of racism, sexism, class relations and the state. The issue of sexuality and heterosexism still remains contained within discourses on reproductive rights and is constructed within a terrain of meaning and practice hegemonized by the Church and the State. It is also clear that the women interviewed do not seek to romanticize feminist and women's politics or make extravagant claims for feminist agendas. As Maria Dirlene T. Marques, an activist in the Workers' Party of Brazil notes, 'The women's movement in Brazil is in an extremely bad state. There are feminists but no functioning feminist movement.' Maria, at the time of the interview, was the only woman member of the regional council of the party and noted that the ratio of men to women in positions of power was 20 to 1 . But the party did vote for a form of positive discrimination for women in 1991 suggesting that all committees should have 30 per cent women members. The workers' movements in Latin America, within both political parties and trade unions, have provided a difficult but important space of contestation for women activists as the interviews attest; one in which issues and policies that respond to feminist questions and demands can be fought over.

But the issue of 'feminism' is still a complex one and as the interviews show often goes unnamed as part of the difficulties of using a language which was, in part, imported and did not seem to address the issues faced by women or the structures which came to bear upon their lives. As Maritza Villavicencio, a Peruvian woman, writes: 'For the women's movement today, terrorism and state repression are the second most important issue after the economic crisis' (p. 69). This is part of the story for so many of the women interviewed in the book. The women from Guatemala and El Salvador have, since the eighties, organized women's projects including a refuge and sought to intervene at the local level in areas of health, income 
generation and safety against state terror. But, as is clear from the Brazilian activist Maria Amelia Teles, local struggles are vitally important but national politics intervenes especially in relation to reproductive rights. She records that: 'Officially, 25 million women have been sterilised, many of them between 15 and 19 years old. That represents a kind of preventative genocide' (p. 75) and Maria Amelia concludes, 'There was never any sexual freedom for women, never any right to desire, never any right to decide freely whether they wanted to have children or not. So the right to choose is our motto and a great dream of ours' (p. 77).

Given the hostile terrain in which women seek to forge their politics, dreams are a crucial part of the ways in which women in Latin America and the Caribbean come together to forge collective subjects as a basis for action, whether in relation to workers' rights, political programmes or the interventions in the forms of communication like the Peruvian journal Mujer y Sociedad first published in $\mathbf{1 9 8 0}$ and now appearing monthly as a supplement in the daily newspaper La República. Cotidiano Mujer from Uruguay began in 1985 and also considered being part of a national daily but found this untenable and now publishes independently. There are feminist magazines and more specialist poetry and art magazines throughout Latin America as well as mujer/fempress, a Latin American women's news agency. These journals and the shared newsline are a vital part of the cross-border communications which sustain women's organizing and cultural production within a great variety of political contexts from the universities and local radio to the grassroots movements.

The costs of an active engagement are poignantly expressed in the interview with Eulalia Yagari Gonzalez, an indigenous woman from Colombia, when she says, 'the right to love and politics', a view detailed in the interview where she expresses the regret that her political engagement means distance from her daughters cared for by relatives and a 'difficult relationship' with a politically active partner. 'We love each other but our political struggle in this quagmire of violence and war makes it impossible for couples to live in peace with one another... Commitment to the cause takes away the ability and the time for love' (p. 141). This book is a testament to these sacrifices and to the ways in which women throughout Latin America and the Caribbean keep alive the dream of love and politics. I am humble in the face of the determination and strength in these chapters and inspired by the commitment, energy and the place of love and the ways of the heart in the women's lives. In part this is set within a discourse of rights but as Esther Andradi, an Argentinian woman, emphasizes, 'the right to be at peace with oneself and the right to pleasure. By no means is pleasure at the end of our list of demands: it is implicit in all our actions, in 
our groups and our togetherness. It is the pleasure which grows from a sense that we are no longer alone. Never again' (p. 6).

This book is a very important book, giving texture and voice to the debates on the role of women in the social movements in Latin America and the Caribbean and to the theorization and practice of postmodern politics.

Contact the Latin American Bureau at 1 Amwell Street, London EC1R 1UL.

Sallie Westwood 